\title{
Optical Coherence Tomography for In Vivo Identification, Characterization and Optimal Treatment of Spontaneous Recanalization of Coronary Thrombus
}

\author{
MIHAIL SPINU $^{1}$, CALIN HOMORODEAN ${ }^{1,2}$, MIHAI CLAUDIU OBER ${ }^{2}$, MARIA OLINIC $^{1,2}$, \\ PETRU ADRIAN MIRCEA ${ }^{1}$ and DAN MIRCEA OLINIC ${ }^{1,2}$ \\ ${ }^{1}$ Department of Internal Medicine, Faculty of Medicine, \\ "Iuliu Haţieganu” University of Medicine and Pharmacy, Cluj-Napoca, Romania; \\ ${ }^{2}$ Department of Interventional Cardiology, Emergency County Hospital, Cluj-Napoca, Romania
}

\begin{abstract}
Background/Aim: Spontaneous recanalization of coronary thrombus (SRCT) is a rare in vivo appearance, with a nonspecific angiographic aspect. The aim of this study was to investigate the importance of optical coherence tomography (OCT) use for SRCT identification, characterization of pathogenic mechanisms and optimal treatment. Patients and Methods: We retrospectively analyzed all patients with angiographic suspicion of SRCT who underwent coronary angiography for suspected coronary artery disease and afterward investigated by OCT imaging. Results: We identified 28 cases with angiographic suspicion of SCRT $(0.41 \%$ of CA) and confirmed it in 4 patients $(0.05 \%$ of CA). OCT provided insight about the underlying SRCT mechanism: possible complicated atherosclerotic plaques in two cases and, respectively, spontaneous coronary artery dissection in other two cases. OCT provided accurate lesion assessment and offered optimal PCI materials selection. Conclusion: Besides providing the diagnosis, OCT also improved characterization of SRCT pathogenic mechanisms, in the four confirmed SRCT cases, supporting the role of coronary wall in situ complications, namely dissection of an atherosclerotic plaque or spontaneous dissection of a normal coronary wall.
\end{abstract}

This article is freely accessible online.

Correspondence to: Calin Homorodean $\mathrm{MD}, \mathrm{PhD}$, Medical Clinic no. 1, 3-5, Clinicilor street, 400006 Cluj-Napoca, Romania. Tel: +40741025342, email: chomorodean@yahoo.com

Key Words: Spontaneous recanalization of coronary thrombus, optical coherence tomography, complicated atherosclerotic plaque, spontaneous coronary dissection, PCI optimization.
Spontaneously recanalized coronary thrombus (SRCT) was, for the first time, observed on histopathology findings, in autopsy series, and characterized by multiple channels divided by thin septa, communicating with each other and, proximally and distally, with the normal coronary lumen (1).

The in vivo appearance of SRCT is a rare finding, and is possibly underdiagnosed, due to the limitations of standard coronary angiography (CA) (2). The first ever in vivo identification of SRCT was performed by Terashima et al. (3) in 2002, using intravascular ultrasound imaging (IVUS), describing a lotus-root appearance in the mid left anterior descending artery (LAD) of a 21 years old patient with suspected Kawasaki disease, with a history of sudden cardiac arrest at the age of one year. Since then, availability of intravascular imaging and the increasing awareness of interventional cardiologists brought to surface this pathology. Availability of optical coherence tomography (OCT), an intra-coronary imaging technique with a resolution 10 times higher than IVUS, further increases the possibility of SRCT identification (2).

OCT is a well recognized tool for the analysis of the atherosclerotic plaque morphology and identification of vulnerable and complicated plaques (4). OCT also has increasing clinical indications (4), with an emphasis on its role in the decision for percutaneous coronary interventions (PCI), in acute coronary syndromes (ACS) with nonsignificant CA lesions $(5,6)$. Experience concerning OCT use for optimization of PCI is also increasing (7-9).

To date, there are several reports on SRCT, regarding clinical presentation, angiographic aspect (2, 3, 10-32), OCT description (2, 10-23, 26-32) and treatment options, with imprecise data regarding its underlying pathogenic mechanisms $(14,17,20-22,25,30-32)$. This article investigated the importance of OCT use for: (i) establishing the real-life SRCT prevalence, in patients with CA suspected SRCT; (ii) identification of the true severity of SRCT 
lesions; (iii) selection of PCI indication and optimal material selection; (iv) investigating SRCT pathogenic mechanisms, including the potential role of atherosclerotic, vulnerable and complicated plaques, as well as of in-wall spontaneous dissection.

\section{Patients and Methods}

Study population. This study retrospectively analyzed all 6,743 patients who underwent CA for suspected coronary artery disease (CAD), in a single tertiary center in Romania (Cluj County Emergency Hospital, Department of Interventional Cardiology), over a period of 7 years (January 2012 - May 2019). There were 5,605 patients with ACS: 2,177 ST segment elevation myocardial infarction (STEMI), 1,384 non-ST segment elevation myocardial infarction (NSTEMI), 2,045 unstable angina (UA) and 1137 stable CAD (stable angina pectoris or silent ischemia patients). Patients with angiographic suspicion of SRCT lesion were investigated by OCT imaging, in order to confirm SRCT diagnosis, to investigate SRCT underlying pathogenic mechanisms and to guide PCI.

Informed consent was obtained before the invasive procedure. Clinical data and angiographic examinations were stored in the hospital database and in a dedicated catheterization laboratory database, using our preexisting experience of structured databases (33-35).

CA and OCT acquisition indications, technique and analysis. CA was performed on Siemens Coroskop T.O.P and Siemens Artis Zee angiographs (Siemens Healthineers, Erlangen, Germany), in patients with suspected CAD. Severity of coronary stenosis was assessed visually and by quantitative coronary analysis (QCA). The highest degree of stenosis severity, usually the area stenosis severity provided by QCA, was considered. Angiographic criteria associated with a SRCT suspicion were pseudo-dissection, braided filling defect and haziness, with an irregular and poly-lobular artery outline and more often a combination of those (2).

OCT imaging was performed in patients with SRCT suspicion on CA. OCT images were acquired with a commercially available system (ILUMIEN OPTIS OCT Intravascular Imaging System, St Jude Medical, St. Paul, MN, USA), using an over the wire OCT catheter (C7 Dragonfly ${ }^{\mathrm{TM}}$ and Dragonfly ${ }^{\mathrm{TM}}$ OPTIS $^{\mathrm{TM}}$, St. Jude Medical, St. Paul, MN, USA). The entire length of the region of interest was scanned using the integrated automated pullback device at $20 \mathrm{~mm} / \mathrm{s}$. During image acquisition, coronary blood flow was replaced by continuous flushing of contrast medium directly from the guiding catheter. All images were recorded digitally, stored, and analyzed using proprietary software (St. Jude Medical, St. Paul, MN, USA) in concordance with standard consensus of OCT use (5).

OCT was performed freely, with no restrictions, by all three senior interventional cardiologists during working hours and, two days each week, 24/24 h, for emergency situations like ACS. OCT was performed only on the coronary vessel with CA suspicion of SRCT. SRCT was identified on OCT as a structure with multiple channels, divided by smooth, high-luminosity, strong reflection and weak attenuation septa, communicating with each other and, proximally and distally, with the normal coronary lumen (2).

In all patients in whom OCT identified SRCT as the lesion responsible for the angiographic stenotic appearance, the degree of stenosis was re-graded using OCT criteria. OCT quantification of coronary lesion severity was made using the proprietary software, as area stenosis compared to largest pre-lesion reference area. The minimum lumen area (MLA) of SRCT was calculated as the sum of MLAs of each SRCT channels in the narrowest site of the lesion. An OCT area stenosis of at least $70 \%$ was considered as significant stenosis. An indication for PCI was made according to the presence of ischemia, objectified by symptoms, electrocardiogram and echocardiogram changes. Myocardium viability was established by echocardiogram changes: hypokinesia - suggesting viability and by Thallium scan in case of a/dyskinesia. We assessed lesion characteristics (e.g. length, reference vessel diameter) on OCT, in order to optimize selection of PCI materials. A comparison was made with lesion characteristics on CA.

A post-procedural detailed analysis of OCT images was performed in patients with SRCT diagnosis, in order to characterize the morphology of the underlying SRCT coronary wall. We investigated the presence of atherosclerotic markers (lipid infiltration, intimal thickening), of high-risk plaques (necrotic core, thin cap fibro-atheroma, macrophage infiltration, hypervascularization) and, respectively, of complicated plaques (intra-plaque hemorrhage, dissection, plaque rupture, erosion and ulceration) (3). The topography of these parameters, in relation to SRCT, was also studied.

In order to provide an accurate review of the literature an extensive search in the PubMed Central and MEDLINE databases was made. All known terms related to SRCT were searched for: "honey-comb like lesion", "lotus-root lesion", "swiss-cheese lesion" and "spider-web lesion".

Follow-up of patients was performed at the end of this study by visits to the clinic or by phone interrogatory, with a focused interest on major adverse cardiac and cerebral events (MACCE), a composite criterion consisting of death from cardiac causes, ischemic or hemorrhagic stroke, myocardial infarction, or need for myocardial revascularization.

All procedural costs of CA, PCI and OCT imaging were supported by the Romanian National Interventional Cardiology Healthcare program.

The study complies with the Declaration of Helsinki on human research and was approved by our local Study Committee (provided in Supplementary data - original informed consent; authorized translated informed consent; official approvals from our local Study Committee).

\section{Results}

During the 7-year investigation period, there were $28 \mathrm{CA}$ suspicions of SRCT, out of the $6,743 \mathrm{CA}(0.41 \%)$. The clinical condition was represented by STEMI in 13 patients, NSTEMI in 4 patients, UA in 9 patients and stable CAD in 2 patients. OCT was performed in all 28 patients with CA suspicion of SRCT. OCT confirmed SRCT in only 4 cases $(14.3 \%)$, which represent $0.05 \%$ of the total $6,743 \mathrm{CA}$ and $0.09 \%$ when referred to our 4302 PCIs performed during the investigated period.

Suspected SRCT on CA were associated with significant angiographic stenosis in only 7 of the 28 patients $(25 \%)$, none with OCT confirmed SRCT. Within the 21 patients' 
Table I. General clinical patient characteristics, cases 1 to 4 .

\begin{tabular}{|c|c|c|c|c|}
\hline & Case no. 1 & Case no. 2 & Case no. 3 & Case no. 4 \\
\hline Gender & Female & Male & Male & Male \\
\hline Age & 43 & 59 & 67 & 41 \\
\hline Hypertension & Yes & Yes & Yes & No \\
\hline Diabetes mellitus & No & No & No & No \\
\hline Dyslipidemia & No & Yes & No & No \\
\hline Renal insufficiency & No & No & No & No \\
\hline Overweight & No & Yes & No & No \\
\hline Smoking habit & Yes & No & No & Yes \\
\hline Cardiovascular history & No & No & No & No \\
\hline Atrial fibrillation & No & No & No & No \\
\hline Physical examination & Normal & Normal & Normal & Normal \\
\hline Blood work & Normal & $\begin{array}{l}\text { High troponin; } \\
\text { hypercholesterolemia }\end{array}$ & Normal & High troponin \\
\hline Electrocardiogram & $\begin{array}{c}\text { Negative } T \text { waves } \\
\text { in V1-V6 }\end{array}$ & $\begin{array}{l}\text { ST segment elevation in } \\
\text { DII, DIII, aVF }\end{array}$ & $\begin{array}{c}\text { Negative } \mathrm{T} \text { waves } \\
\text { in } \mathrm{V} 3-\mathrm{V} 6\end{array}$ & $\begin{array}{c}\text { ST segment elevation } \\
\text { in V1-V4, negative T } \\
\text { waves in DI, aVL, V4-V6 }\end{array}$ \\
\hline Echocardiogram & $\begin{array}{l}\text { LV anterior wall } \\
\text { hypokinesia; } \\
45 \% \text { LVEF }\end{array}$ & $\begin{array}{c}\text { LV inferior and anterior } \\
\text { wall hypokinesia; } \\
45 \% \text { LVEF }\end{array}$ & $\begin{array}{c}\text { LV lateral wall } \\
\text { akinesia; } 40 \% \text { LVEF, } \\
\text { Second grade ischaemic } \\
\text { mitral regurgitation }\end{array}$ & $\begin{array}{l}\text { LV anterior wall akinesia; } \\
\text { LV dilatation, apical } \\
\text { aneurysm without } \\
\text { thrombus, } 38 \% \text { LVEF }\end{array}$ \\
\hline Diagnosis & Unstable angina & Inferior STEMI & Unstable angina & Anterior STEMI in evolution \\
\hline
\end{tabular}

LV: Left ventricle; LVEF: left ventricle ejection fraction; STEMI- ST: elevated myocardial infarction.

Table II. Angiographic characteristics, cases 1 to 4 .

\begin{tabular}{lcccc}
\hline & Case no. 1 & Case no. 2 & Case no. 3 & Case no. 4 \\
\hline CA findings & $\begin{array}{l}\text { Single vessel disease } \\
\text { (LAD stenosis) }\end{array}$ & $\begin{array}{c}\text { Two vessels disease } \\
\text { (RCA occlusion and } \\
\text { Diagonal stenosis) }\end{array}$ & $\begin{array}{c}\text { Two vessels disease } \\
\text { (LAD stenosis and distal }\end{array}$ & $\begin{array}{c}\text { Single vessel disease } \\
\text { (LAD stenosis) }\end{array}$ \\
SRCT vessel & Diagonal artery & LAD & Yes & LAD \\
Culprit lesion & Yes & No; Culprit was & 30 & Yes \\
Lesion severity (\%) & 50 & 40 & 20 & 50 \\
Lesion length (m) & 15 & 22 & 3 & 40 \\
TIMI flow & 3 & 3 & & 3 \\
\hline
\end{tabular}

CA: Coronary angiography; LAD: left anterior descending artery; LCX: left circumflex artery; RCA: right coronary artery; SRCT: spontaneous recanalization of coronary thrombus; TIMI: thrombolysis in myocardial infarction.

subgroup with borderline lesion on CA, there were 4 OCT confirmed SRCT patients.

Clinical data of confirmed SRCT patients. Table I summarizes the relevant clinical information, for each of the 4 SRCT patients. There were 3 males and one female, with a median age of 53 years. Clinical diagnosis was UA in two patients and inferior and anterior STEMI in other two. All patients were without cardiovascular (CV) history and without atrial fibrillation. All patients had CV risk factors, ranging from one to three $\mathrm{CV}$ risk factors for each patient. $\mathrm{CV}$ physical examination was normal in all patients. Electrocardiogram showed negative $\mathrm{T}$ waves in pre-cordial leads in the two UA patients, while elevated ST segment in inferior and anterior leads were present in the inferior and anterior STEMI patients. Left ventricle motion abnormalities and moderate left ventricle ejection fraction reduction were observed on three patients, while LV dilatation and anterior LV wall akinesia and apical aneurysm were observed on the forth patient. The blood work was abnormal only in the STEMI patients. 


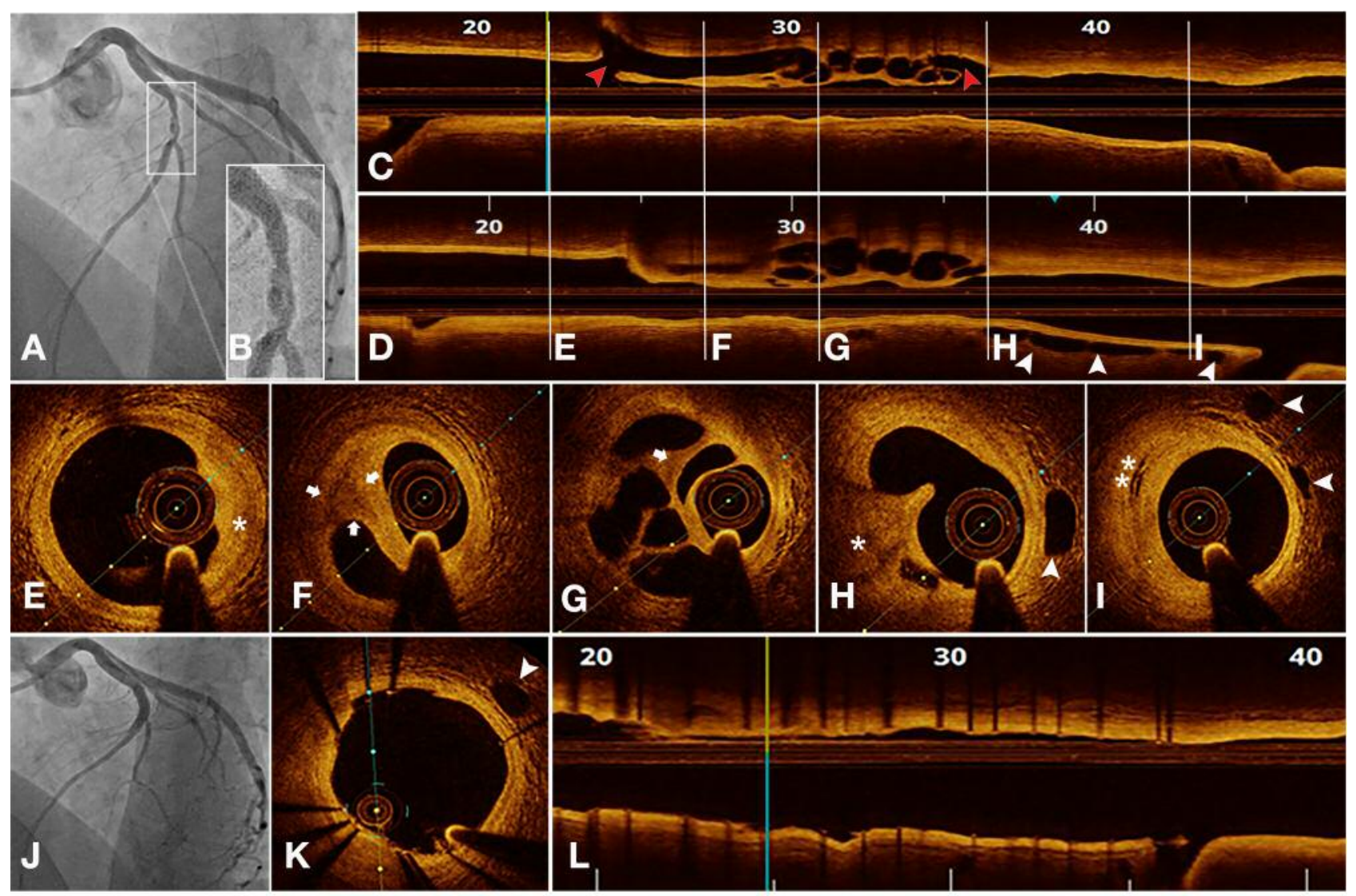

Figure 1. First spontaneous recanalization of coronary thrombus (SRCT) case. A: Angiographic view; B: Detailed angiographic view; longitudinal views: $C$ and D, between red arrowheads; transversal views: $F, G$ and H. OCT imaging: an SRCT structure with multiple channels divided by smooth, high-luminosity, strong reflection and weak attenuation septa; Inside septa, signal-poor, darker tissue areas are visualized (white arrows in $F$ and $G$ ): linked by previous histopathology studies (2) to proteoglycan-rich tissue. Other signal-poor regions in the arterial wall showing some degree of posterior attenuation may correspond to lipid atherosclerotic plaques: asterisk in $E$ and $H$. White arrowheads in $D, H, I$ and $K:$ The lesions were hypervascularized, with a large vasa vasorum. Double asterisk in I: A possible intra-plaque dissection/hemorrhage was imaged proximally to the SRCT. J: Optimal angiographic PCI result. L: Optimal post PCI OCT result.

Coronary angiography data in the SRCT confirmed patients (Table II). In both UA patients, SRCT lesions were the culprit ones, located on the mid LAD (Figures 1, 2A and 2B). In the anterior STEMI patient, the SRCT lesion, situated in the proximal and mid-LAD, was the culprit lesion as well (Figure 3). In patients no. 1 and no. 4 , there was a single vessel disease. In patient no. 2 , a two-vessels disease was present, due to coexisting chronic occlusion of the left circumflex artery (LCX).

In the inferior STEMI patient, in whom the acute coronary occlusion was situated on the proximal right coronary artery (RCA), the SRCT lesion was found on the first diagonal artery (Figure 4A).

The thrombolysis in myocardial infarction flow was graded normal in all SCRT arteries. The angiographic appearance of SCRT was a combination of pseudo- dissection and braided filling defect (patients no. 1, 2 and 4) and pseudo-dissection filling defect in one case (patient no. 3). Lesion severity was graded visually and by QCA as 30,40 and $50 \%$ for both no. 1 and 4 cases. The length of suspected SRCT was measured at 15, 20, 22 and $40 \mathrm{~mm}$, respectively.

OCT data in confirmed SRCT patients (Table III). In all patients with confirmed SRCT, in whom CA revealed borderline lesions, OCT reassessed lesions as significant, with an indication for PCI. As compared to CA, lesion length was longer on OCT, while vessel diameter was similar. OCT data allowed optimal selection of stent length for PCI.

Detailed post-procedural OCT analysis provided information on the possible SRCT pathogenic mechanisms. OCT identified coronary wall in situ complications, namely dissection of an 

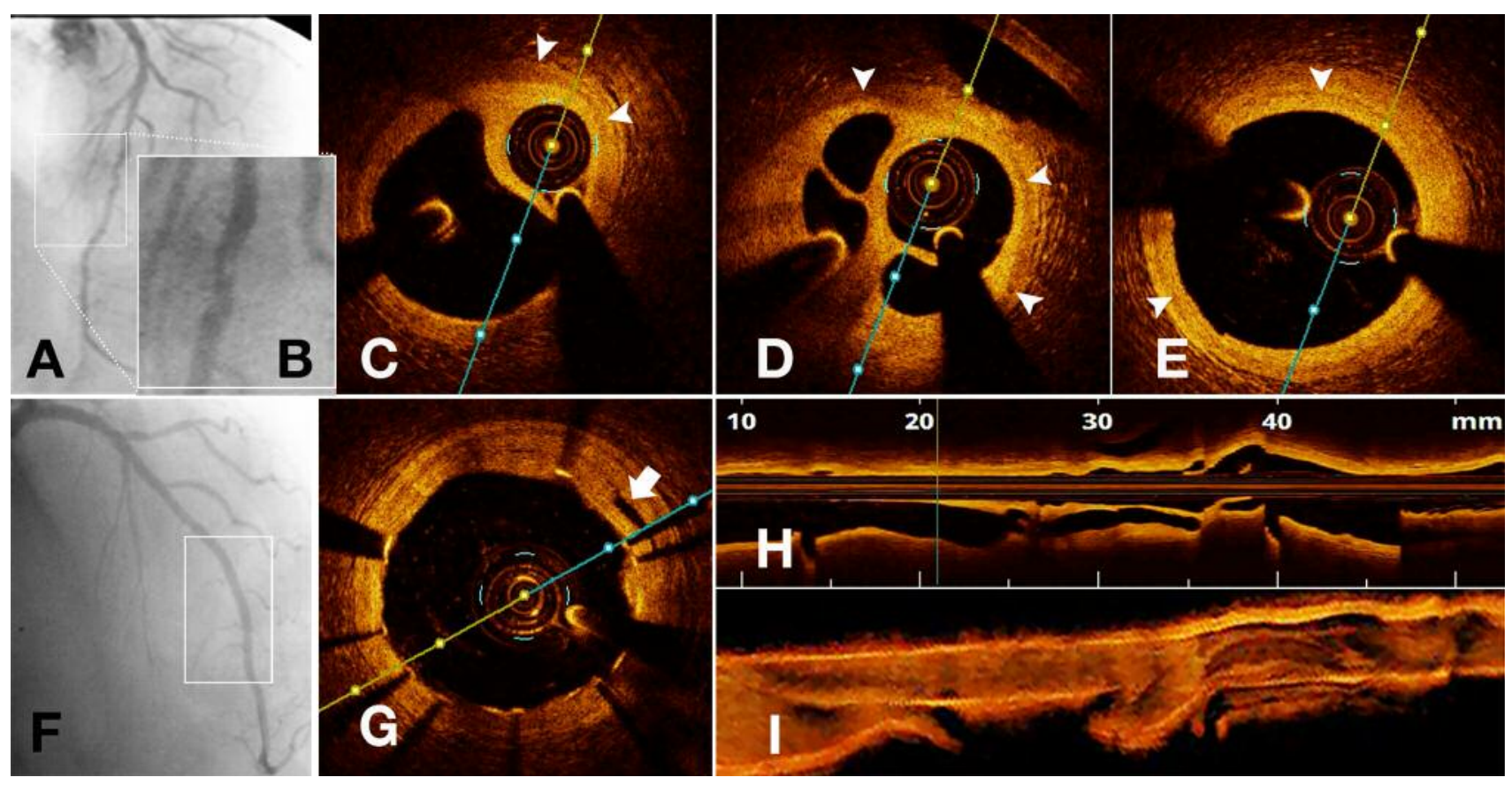

Figure 2. Third spontaneous recanalization of coronary thrombus (SRCT) case. A: Angiographic view. B: Detailed angiographic view. C to E: OCT imaging of an SRCT lesion - transversal views; $C, D$ and $E$ (white arrowheads): The normal, three-layered, coronary wall was observed on the entire length of SRCT, representing normal wall media, seen almost circumferentially in E, with no evidence of atherosclerosis. F: Angiographic optimal PCI result. G: OCT imaging of optimal PCI result (white arrow - SRCT remaining channel). OCT imaging of the SRCT structure: H, longitudinal view; I, three-dimensional reconstruction.

Table III. OCT characteristics, cases 1 to 4.

\begin{tabular}{|c|c|c|c|c|}
\hline & Case no. 1 & Case no. 2 & Case no. 3 & Case no. 4 \\
\hline OCT indication & $\begin{array}{l}\text { Borderline lesion } \\
\text { assessment }\end{array}$ & $\begin{array}{l}\text { Borderline lesion } \\
\text { assessment }\end{array}$ & $\begin{array}{l}\text { Borderline lesion } \\
\text { assessment }\end{array}$ & $\begin{array}{l}\text { Borderline lesion } \\
\text { assessment }\end{array}$ \\
\hline OCT area stenosis & 75 & 80 & 80 & 75 \\
\hline Lesion length & 22 & 28 & 26 & 65 \\
\hline $\begin{array}{l}\text { OCT description: } \\
\text { "Honeycomb" aspect }\end{array}$ & Yes & Yes & Yes & Yes \\
\hline \multicolumn{5}{|l|}{ Atherosclerotic plaque markers } \\
\hline Lipid infiltration & Yes & Yes & No & No \\
\hline Intimal thickening & Yes & Yes & No & No \\
\hline \multicolumn{5}{|l|}{ Markers of high-risk plaques } \\
\hline Thin cap fibro-atheroma & Possible & Possible & No & No \\
\hline Macrophage infiltration & Possible & Possible & No & No \\
\hline Hypervascularization & Yes & Yes & No & No \\
\hline necrotic core & No & No & No & No \\
\hline \multicolumn{5}{|l|}{ Markers of plaque complication } \\
\hline Dissection & Possible & Possible & No & No \\
\hline Plaque rupture & Possible & Possible & No & No \\
\hline Plaque erosion & No & No & No & No \\
\hline Plaque ulceration & No & No & No & No \\
\hline $\begin{array}{l}\text { Markers of coronary } \\
\text { wall complication }\end{array}$ & No & No & Yes & Yes \\
\hline OCT role for therapeutic decision & Yes; Indication for PCI & Yes; Indication for PCI & Yes; Indication for PCI & Yes; Indication for PCI \\
\hline OCT role for PCI guiding & $\begin{array}{l}\text { Optimizing selection } \\
\text { of PCI devices }\end{array}$ & $\begin{array}{l}\text { Optimizing selection } \\
\text { of PCI devices }\end{array}$ & $\begin{array}{l}\text { Optimizing selection } \\
\text { of PCI devices }\end{array}$ & None \\
\hline Treatment option & $\begin{array}{l}\text { Direct } 3 / 24 \mathrm{~mm} \text { DES } \\
\text { implantation }\end{array}$ & $\begin{array}{l}\text { Direct } 3.5 / 30 \mathrm{~mm} \\
\text { DES implantation }\end{array}$ & $\begin{array}{c}\text { Pre-dilatation; } \\
3 / 28 \mathrm{~mm} \text { DES implantation }\end{array}$ & $\begin{array}{l}\text { Conservative } \\
\text { treatment }\end{array}$ \\
\hline
\end{tabular}

OCT: Optical coherence tomography; PCI: percutaneous coronary intervention; DES: drug eluting stent. 


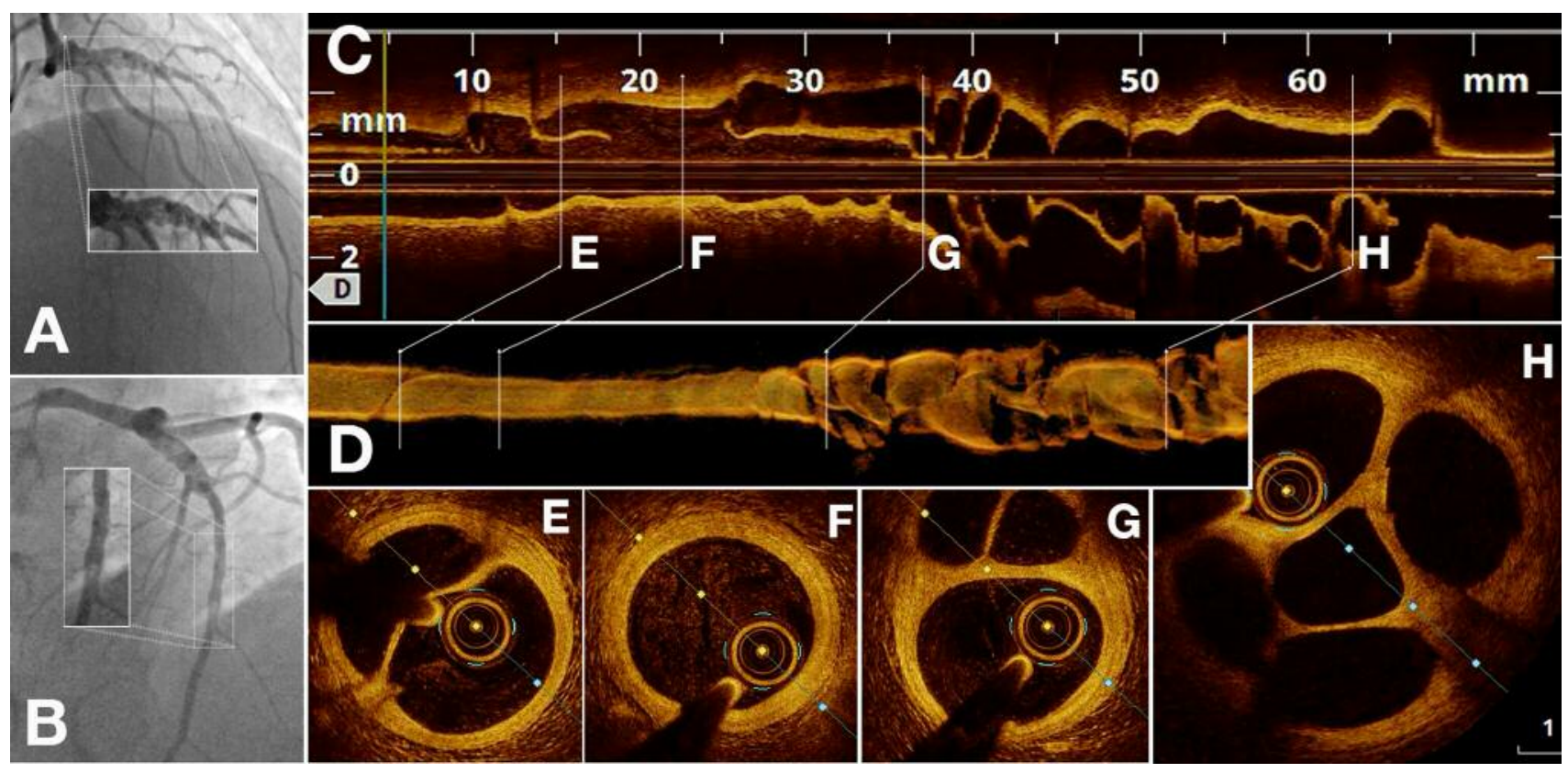

Figure 3. Fourth spontaneous recanalization of coronary thrombus (SRCT) case. A patient with a long lesion including two SRCTs, separated by a normal segment. Angiographic views with details highlighting proximal (A) and distal SRCTs (B). OCT imaging: Longitudinal view (C), 3D reconstruction $(D)$ and transversal views at different levels - distal SRCT $(E)$, proximal SRCT $(G$ and $H)$, with dilated coronary lumen $(H)$. OCT cross-section of the normal segment between the two SRCTs is depicted in F.

atherosclerotic plaque, in the patients no. 1 and 2 , and a normal coronary wall, in the patients no. 3 and 4.

In the first two patients (Figure $1 \mathrm{E}, 1 \mathrm{~F}, 1 \mathrm{H}$, and $4 \mathrm{C}-4 \mathrm{H}$ ), OCT revealed, both in the area of SRCT underlying vessel wall and in adjacent coronary areas (proximal and distal to the lesion), markers of atherosclerosis (lipid infiltration and intimal thickening) and possible markers of high-risk plaques (hypervascularization). In both cases, in the area of SRCT underlying vessel wall, there were several markers of plaque complications (Figures 1 and 4). Proximal to the SRCT, in the entrance area to the SRCT lesion, OCT identified an intra-plaque hemorrhage/dissection in the first case (Figure 1I) and, respectively, a plaque rupture in the second one (Figure 4D). In this latter patient, a possible intimal rupture was also identified in the distal extremity of SRCT (Figure 4F).

In the third and fourth patients (Figures 2 and 3), OCT did not identify atherosclerotic markers. A normal, three layers, coronary wall was observed on the entire length of SRCT. After PCI (in patient no. 3), a linear signal-free space within the media raises the problem of a spontaneous coronary dissection, probable initiating the SRCT lesion. For the fourth patient, beside absence of atherosclerotic markers, the considerable length and size of the lesion may support spontaneous dissection as the nidus for thrombus formation.
Treatment options in OCT confirmed SRCT cases. PCI with DES implantation was performed in patients no. one, two and three, with direct stenting in two patients (Figure 1E, 1F and $1 \mathrm{G}$; Figure $2 \mathrm{~F}$ and $2 \mathrm{G}$ ) and with balloon pre-dilatation in the other one (Figure $4 \mathrm{~B}, 4 \mathrm{H}$ and $4 \mathrm{~J}$ ). There were no periprocedural complications. All three patients were discharged in a good clinical, symptom-free status, on dual antiplatelet, beta-blocker, statin, and angiotensin converting enzyme inhibitor therapy. For these three patients there was a strong clinical improvement after PCI.

For the fourth patient, a Thallium scan test was performed in order to assess the myocardium viability, which showed large areas of necrosis, making revascularization unnecessary. For this case, a conservative approach was established, with dual antiplatelet, beta-blocker, statin, angiotensin converting enzyme inhibitor, oral loop and anti-aldosterone diuretic therapy, with a good clinical condition at the last control.

A median follow-up of 29 months was made in all 4 patients (Case 1-39 months, case 2-7 months, case 3-65 months and case 4-5 months) with no MACCE reported.

\section{Discussion}

Our study confirms that SRCT is a very rare finding, with only $28 \mathrm{CA}$ suspected SRCT lesions in the 6,743 patients 


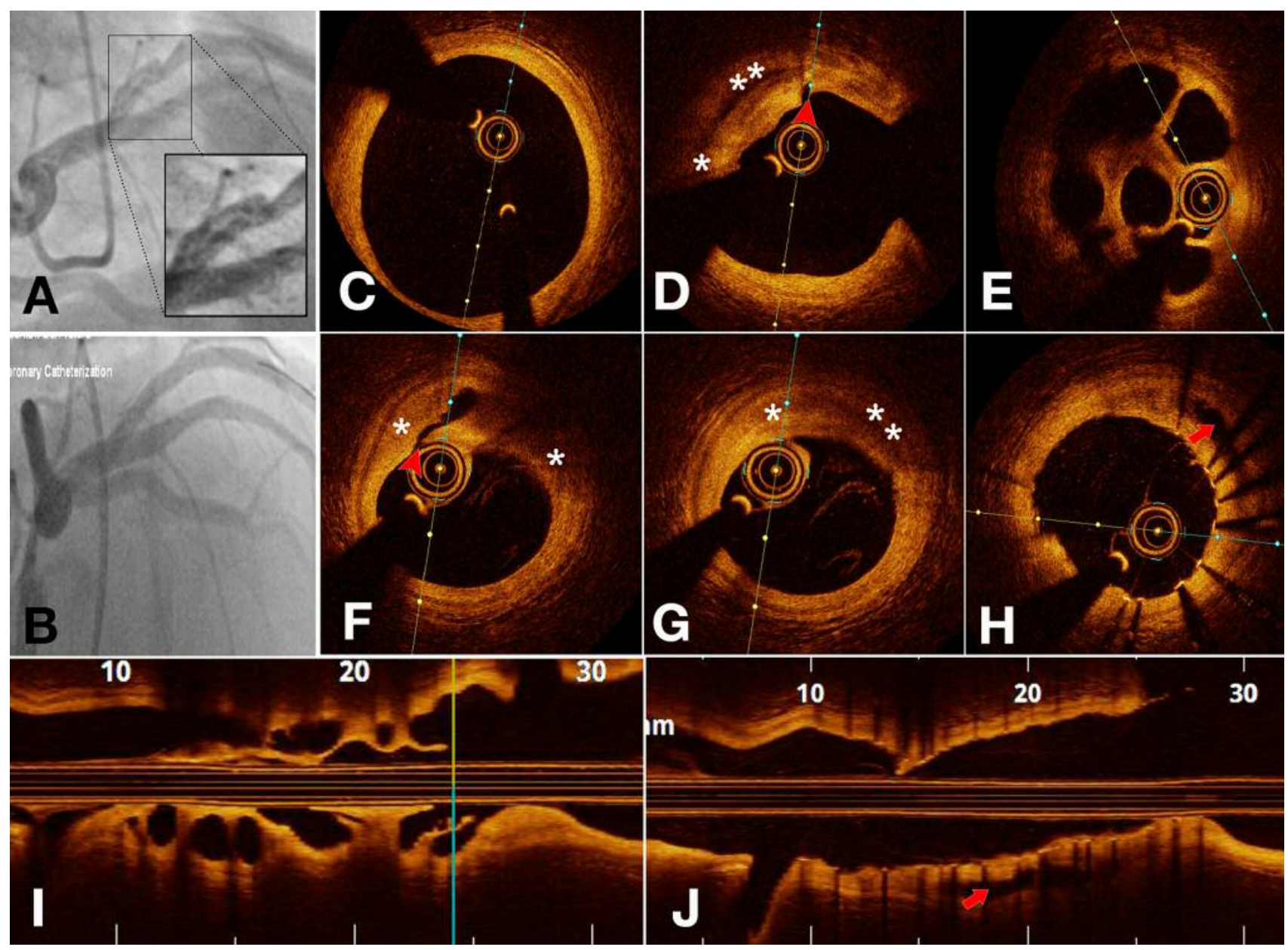

Figure 4. Second spontaneous recanalization of coronary thrombus (SRCT) case. A (with detailed view, showing the characteristic braided and pseudodissection aspect): Angiographic view. B: Optimal post-PCI angiography. C: Part of the coronary vessel proximal to the SRCT. Asterisk (*) in D, F and G: OCT imaging; an SRCT lesion, superimposed on an atherosclerotic plaque with signal-poor areas, representing lipid accumulation. Double asterisk (**) in D and G: A possible intra-plaque dissection/hemorrhage was imaged both proximally and distally to the SRCT. E: SRCT channels. The proximal and distal SRCT entry point can be precisely localized: D: red arrowhead-proximal entry point and F: red arrowhead, distal exit point. A part of SRCT channels were still identified on OCT, after PCI: H and J: red arrows: SRCT channels. I: OCT longitudinal view of SRCT.

with suspected CAD $(0.41 \%)$ and, moreover, only 4 OCT confirmed SRCT lesions ( $0.05 \%$ of the CA). Prevalence of SRCT lesions was $0.09 \%$ when referred to our 4,302 PCI during the investigated period. This result is consistent with previous findings. In the largest cohort of SRCTs ever reported (10), authors identified 33 SRCT cases out of 31,500 PCIs, during a 5-year period. Considering these findings, SRCT prevalence was estimated around $0.1 \%$ of PCIs.

Besides the previous mentioned study (10), exhaustive search of the literature showed 23 case reports $(3,11-32)$ and one study (2) on 6 other cases reported to date, totalizing 62 SRCT cases (Table IV), focusing mainly on the clinical presentation, angiographic and intravascular imaging aspect, treatment modality and very few comments related to the mechanism for thrombus formation. Also, there are scarce data on prognostic and follow up of the SRCT patients.

It was previously believed that the true prevalence of SRCT lesions might be underestimated, due to its angiographic non-specific aspect: namely haziness, braided and pseudo-dissection filling defects. This angiographic aspect can be related to other various conditions: fresh thrombosis on plaque rupture/erosion, spontaneous dissection, aneurysm or heavy calcification (2, 36-40). The diagnosis becomes possible only by intravascular imaging. 
Table IV. All SRCT-related articles published to date.

\begin{tabular}{|c|c|c|c|c|c|c|c|}
\hline Authors & $\begin{array}{l}\text { Patients } \\
(\mathrm{M} / \mathrm{F})\end{array}$ & $\begin{array}{l}\text { Clinical } \\
\text { diagnosis }\end{array}$ & $\begin{array}{l}\text { SRCT } \\
\text { vessel }\end{array}$ & $\begin{array}{l}\text { Angiographic } \\
\text { aspect }\end{array}$ & $\begin{array}{l}\text { Intravascular } \\
\text { imaging }\end{array}$ & $\begin{array}{l}\text { Treatment } \\
\text { option }\end{array}$ & Origin \\
\hline Kang SJ et al. (2) & $6(3 \mathrm{M} / 3 \mathrm{~F})$ & $\begin{array}{c}\text { UA: } 4 \mathrm{p} \\
\text { SCAD: } 2 \mathrm{p}\end{array}$ & $\begin{array}{l}\text { LAD } 2 p \\
\text { RCA } 4 p\end{array}$ & $\begin{array}{l}\text { Haziness and } \\
\text { pseudo- } \\
\text { dissected: } 6 \mathrm{p}\end{array}$ & both & $\begin{array}{c}\text { PCI with DES } \\
5 \text { Conservative } 1\end{array}$ & $\begin{array}{l}\text { Plaque rupture, } \\
\text { embolic or } \\
\text { spontaneous } \\
\text { dissection }\end{array}$ \\
\hline Terashima $\mathrm{M}$ et al. (3) & $1 \mathrm{M}$ & undeclared & LAD & Haziness & IVUS & Not disclosed & Not mentioned \\
\hline Souteyrand G et al. (10) & $\begin{array}{c}33(23 \mathrm{M} / \\
10 \mathrm{~F})\end{array}$ & $\begin{array}{c}\text { STEMI: } 2 \mathrm{p} \\
\text { NSTEMI: } 8 \mathrm{p} \\
\text { SCAD: } 11 \mathrm{p} \\
\text { silent ischemia: } \\
12 \mathrm{p}\end{array}$ & $\begin{array}{l}\text { LAD } 14 p \\
\text { LCX 3p } \\
\text { RCA } 17 p\end{array}$ & $\begin{array}{l}\text { Haziness: } 2 \mathrm{p} \text {; } \\
\text { braided: } 21 \mathrm{p} \text {; } \\
\text { pseudo- } \\
\text { dissected: } 10 \mathrm{p} \text {; } \\
\text { Occlusion: } 1 \mathrm{p}\end{array}$ & OCT & $\begin{array}{l}\text { PCI with DES } 31 ; \\
\text { Conservative } 3\end{array}$ & Not mentioned \\
\hline Cho JM et al. (11) & $1 \mathrm{M}$ & silent ischemia & LAD & Haziness & OCT & Not disclosed & Not mentioned \\
\hline Kato M et al. (12) & $1 \mathrm{M}$ & silent ischemia & RCA & Occlusion & OCT & Not disclosed & Not mentioned \\
\hline Estévez-Loureiro R et al. (13) & $1 \mathrm{M}$ & SCAD & LAD & Pseudo-dissected & both & Not disclosed & Not mentioned \\
\hline Toutouzas K et al. (14) & $1 \mathrm{M}$ & STEMI & LAD & Haziness & OCT & PCI with DES & Embolic \\
\hline $\begin{array}{l}\text { Gómez-Monterrosas O } \\
\text { et al. (15) }\end{array}$ & $1 \mathrm{M}$ & STEMI & LAD & Haziness & OCT 1 & Bioresorbable scaffold & Not mentioned \\
\hline Koyama K et al. (16) & $1 \mathrm{M}$ & STEMI & $\mathrm{RCA}$ & Braided & OCT & PCI with DES & Not mentioned \\
\hline Musashi M et al. (17) & $1 \mathrm{M}$ & SCAD & LAD & Haziness & OCT & PCI with DES & Embolic \\
\hline Yang DH et al. (18) & $1 \mathrm{M}$ & UA & LAD & Occlusion & OCT & Not disclosed & Not mentioned \\
\hline Watanabe Y et al. (19) & $1 \mathrm{M}$ & SCAD & LAD & Haziness & OCT & Drug eluting balloon & Not mentioned \\
\hline Suzuki S et al. (20) & $1 \mathrm{M}$ & silent ischemia & RCA & Haziness & OCT & PCI with DES & Embolic \\
\hline Kimura T et al. (21) & $1 \mathrm{M}$ & SCAD & RCA & Haziness & OCT & PCI with DES & Embolic \\
\hline Seike F et al. (22) & $1 \mathrm{M}$ & silent ischemia & LAD & Haziness & OCT & PCI with DES & Embolic \\
\hline Dai K et al. (23) & $1 \mathrm{M}$ & undeclared & RCA & Occlusion & OCT & Not disclosed & Not mentioned \\
\hline Karamasis GV et al. (24) & $1 \mathrm{M}$ & SCAD & LAD & Haziness & IVUS & PCI with DES & Not mentioned \\
\hline Haraki T et al. (25) & $1 \mathrm{M}$ & SCAD & LAD & Pseudo-dissected & IVUS & PCI with DES & Embolic \\
\hline Silenzi S et al. (26) & $1 \mathrm{M}$ & silent ischemia & RCA & Braided & OCT & PCI with DES & Not mentioned \\
\hline Niizeki T et al. (27) & $1 \mathrm{M}$ & UA & RCA & Haziness & OCT & Not disclosed & Not mentioned \\
\hline Khoueiry GM et al. (28) & $1 \mathrm{M}$ & silent ischemia & RCA & Haziness & OCT & PCI with DES & Not mentioned \\
\hline Fujino Y et al. (29) & $1 \mathrm{M}$ & SCAD & LCX & Occlusion & OCT & PCI with DES & Not mentioned \\
\hline Sakurai $\mathrm{S}$ et al. (30) & $1 \mathrm{M}$ & SCAD & RCA & Braided & both & Not disclosed & Spontaneous dissection \\
\hline Lin M et al. (31) & $1 \mathrm{M}$ & SCAD & RCA & Haziness & both & PCI with DES & Spontaneous dissection \\
\hline Kadowaki H et al. (32) & $1 \mathrm{M}$ & SCAD & LAD & Haziness & OCT & PCI with DES & Embolic \\
\hline
\end{tabular}

M: Male; F: female; STEMI: acute ST elevated myocardial infarction; NSTEMI: acute non-ST elevated myocardial infarction; UA: unstable angina; SCAD: stable coronary artery disease; LAD: left anterior descending coronary artery; RCA: right coronary artery; LCX: left circumflex coronary artery; OCT: optical coherence tomography; IVUS: intravascular ultrasound; PCI: percutaneous coronary intervention; DES: drug-eluting stent; p: patients.

The reported angiographic aspect was described as braided in 24 cases $(10,16,25,30)$, as haziness in 18 cases $(2,3,10$, $11,14,15,17,19-22,24,27,28,31,32)$, as pseudodissection in 15 cases $(3,10,13,25)$ and as occlusions in 5 cases $(10,12,18,23,29)$. Our study shows that only $14.3 \%$ of the CA suspected SRCT cases (4 out of 28) were truly OCT confirmed SRCT. Another finding of our study is that the angiographic combination of braided and pseudodissection aspect is highly suggestive for SRCT (3 out of the 28 suspected SRCT and all 3 being confirmed as truly SRCT).

All our 4 patients with confirmed SRCT lesion had borderline CA lesions, but significant OCT stenosis. OCT also identified longer lesion length, as compared to CA alone, therefore supporting optimal PCI material selection. We performed PCI on our first three patients based on strong clinical (ACS), ECG and echocardiogram findings suggesting ischemia and myocardium viability. Beside the acuteness of the clinical picture, our decision to perform immediate PCI was also supported by data from previous papers suggesting a greater hemodynamic impact of SRCT than that expected from stenosis severity (2). The discordance between lumen reduction and symptomatic impact may be due to the tortuosity of the channels (2). Therefore, even if SRCT lesion is not significant on CA, the blood flow might be severely impaired, due to SRCT spatial conformation (2). In the largest registry to date of SRCT lesions, PCI was performed immediately in $91 \%$ of 
cases (10). The same study has shown an OCT measured lumen reduction between 20 and $93 \%$ (10). Assessment of SRCTs with fractional flow reserve (FFR) would have been of great interest because there are no data about its functional impairment. Nevertheless, there are several reports $(41,42)$ that suggest that the use of FFR in settings of ACS is associated with greater risks when compared to SCAD.

Besides the crucial role of OCT in providing lesion severity assessment, identification of SRCT as target lesion provided a support for immediate PCI, as mentioned above, as well as it helped us in the process of selecting PCI materials and assessment of post PCI result. It is well known the fact that sub-optimal PCI result (malposition, edgedissection, under-expansion) is responsible for future MACCE, thus, the use of OCT for PCI guidance enriches the chances for a good immediate and late outcome (5).

In our group, there was symptomatic improvement in all these patients after revascularization. For the fourth patient a conservative treatment approach was established, due to imagistic findings of LV anterior wall and apex necrosis areas without viability at myocardial scintigraphy. There were no MACCE reported during the follow-up period.

Our treatment approach was similar to previous data, represented by the 62 reported SRCT cases, of whom most had PCIs: DES placement in 49 cases $(2,10,14,16,17,20$ 22, 24-26, 28, 29, 31, 32), bioresorbable vascular scaffolds implantation in one case (15) and drug eluting balloon angioplasty in another one case (19). Conservative treatment was selected for 3 cases $(2,10)$, suggesting a non-significant lesion, while the treatment option was not disclosed in the remaining 8 reported cases $(3,11-13,18,22,27,30)$.

The SRCT underlying mechanism is not known. A possible cardio-embolic origin was suggested in 7 reported cases $(14,17,20-22,25,32)$. Post-dissection thrombus was suggested in two reported cases $(30,31)$. In the other reported cases, the suspected SRCT pathogenic mechanism is not mentioned.

OCT performed in our SRCT cases support the thesis of coronary wall complications as the origin for thrombus formation. We believe that in two of our four patients, OCT identified coronary wall in situ dissection of an atherosclerotic plaque, while a spontaneous dissection of a normal coronary wall was the nidus for thrombus formation in the third and fourth patients. Arguments for spontaneous dissection are absence of any atherosclerotic markers and embolic sources and, respectively, in the fourth case, the length and the dilatation of the coronary vessel (a lesion too long to represent an embolus or in situ thrombosis).

Topography of SRCT lesions, in our cases, was similar to the one in the literature, the affected coronary arteries being LAD in 26 cases $(2,10,11,13-15,17-19,22,24,25,32)$, $\mathrm{RCA}$ in 32 cases $(2,10,12,16,20,21,23,26-28,30,31)$ and LCX in 4 cases $(10,29)$. Diagonal artery is found in our study to be site for SRCT, too.

SRCT were identified, in our study, as culprit or non-culprit lesions for ACS patients. Data from the literature show that the 62 SRCT lesions may be asymptomatic - 20 cases (10-12, $20,22,26,28)$ or symptomatic, associated with stable CAD 23 cases $(2,10,13,17,20,21,24,25,29-32)$, UA - 5 cases $(2,18,27)$ or acute STEMI - 12 cases $(2,10,14-16)$. Other two cases had an undeclared clinical condition $(3,23)$.

Gender prevalence related to SRCT is similar, in our study, to the reports in the literature. SCRT lesions has apparently a higher prevalence in men: 3 out of 4 in our study and 44 out of 62 in previously reported patients $(2,3$, 10-32).

OCT was the only SRCT imaging method for our study, as it was for 56 of the 62 cases reported in the literature (2, 10-12, 14-23, 26-29, 31). IVUS was used in 3 cases $(3,24$, 25), while both OCT and IVUS were used in other 3 cases (13, 30, 31). Terms used for SRCT description were "honeycomb-like structure" - 13 cases (14-17, 19-22, 25-28, $31)$, "lotus root structure" - 38 cases $(3,10,12,23,30,32)$, "swiss cheese structure" - 8 cases $(2,18,25)$ and SRCT in only 3 cases $(11,13,24)$.

Our study illustrates OCT real-life clinical use in SRCT management, not only for diagnosis and therapeutic decisions role, but also contribute to the understanding of SRCT lesions underlying mechanisms.

Limitations. Our study is an observational, retrospective one, with a small number of patients. We should point out that some short SRCTs, with a small number of lumens might be misconsidered as simple complicated atherosclerotic plaques, or worse, might remain simply unrecognized. Also, for the objective identification of hemodynamic lesion impairment, a fractional flow reserve assessment would have been of great interest.

OCT pitfalls. OCT has few disadvantages represented by a slightly increase in operating times, contrast agent volume and procedural complications. These disadvantages are overwhelmed by the net advantages offered by OCT use in interventional cardiology, by providing the third dimension to $\mathrm{CA}$, which reflects in the correct diagnosis and, respectively, in a better procedural and clinical outcome. In the specific situation of SRCT, the stenosis severity assessed by OCT may be underestimated as the hemodynamic impact is driven also by the tortuosity of the channels (2).

\section{Conclusion}

SRCT is a very rare in vivo appearance, with a nonspecific angiographic aspect of haziness, braided and pseudodissected filling defect. OCT allowed SRCT diagnosis, 
accurate lesion assessment, optimal PCI materials selection and, more important, improved characterization of SRCT pathogenic mechanisms, in the four confirmed SRCT cases, supporting the role of coronary wall in situ complications, namely dissection of an atherosclerotic plaque or spontaneous dissection of a normal coronary wall.

\section{Conflicts of Interest}

The Authors declare that no conflicts of interest exist with regard to the present study.

\section{Authors' Contributions}

Conceptualization: Mihail Spinu and Dan Mircea Olinic; Data curation: Mihail Spinu and Calin Homorodean; Formal analysis: Calin Homorodean and Maria Olinic; Investigation: Calin Homorodean, Mihai Claudiu Ober and Dan Mircea Olinic; Methodology: Calin Homorodean, Mihai Claudiu Ober, Maria Olinic and Dan Mircea Olinic; Project administration: Mihail Spinu and Petru Adrian Mircea; Resources: Maria Olinic; Software, Mihail Spinu, Calin Homorodean and Mihai Claudiu Ober; Supervision: Petru Adrian Mircea and Dan Mircea Olinic; Validation: Petru Adrian Mircea and Dan Mircea Olinic; Visualization: Petru Adrian Mircea; Writing - original draft: Mihail Spinu; Writing - review \& editing: Dan Mircea Olinic.

\section{References}

1 Friedman M and Van den Bovenkamp GJ: The pathogenesis of a coronary thrombus. Am J Pathol 48(1): 19-44, 1966. PMID: 5902836.

2 Kang SJ, Nakano M, Virmani R, Song HG, Ahn JM, Kim WJ, Lee JY, Park DW, Lee SW, Kim YH, Lee CW, Park SW and Park SJ: OCT findings in patients with recanalization of organized thrombi in coronary arteries. JACC Cardiovasc Imaging 5(7): 725-732, 2012. PMID: 22789941. DOI: 10.1016/j.jcmg.2012.03.012

3 Terashima M, Awano K, Honda Y, Yoshino N, Mori T, Fujita H, Ohashi Y, Seguchi O, Kobayashi K, Yamagishi M, Fitzgerald PJ, Yock PG and Maeda K: Images in cardiovascular medicine. "Arteries within the artery" after Kawasaki disease: a lotus root appearance by intravascular ultrasound. Circulation 106(7): 887, 2002. PMID: 12176965. DOI: 10.1161/01.cir.0000030708.86783.92

4 Spînu M, Olinic DM, Olinic M and Homorodean C: In vivo imaging of complicated atherosclerotic plaque - role of optical coherence tomography (OCT). Rom J Morphol Embryol 59(2): 469-478, 2018. PMID: 30173250.

5 Olinic DM, Spinu M, Homorodean C, Ober M and Olinic M: Real-life benefit of OCT imaging for optimizing PCI indications, strategy, and results. J Clin Med 8: 437, 2019. PMID: 30934997. DOI: $10.3390 / \mathrm{jcm} 8040437$

6 Homorodean C, Ober MC, Olinic M, Homorodean R, Hassoune A, Tătaru D, Spînu $M$ and Olinic DM: Takotsubo cardiomyopathy presenting as ST-elevation myocardial infarction: wide triggering spectrum and specific echocardiographical pattern in a consecutive case series report. Med Ultrason 18(4): 475-480, 2016. PMID: 27981281. DOI: $10.11152 / \mathrm{mu}-876$
7 Homorodean C, Ober MC, Iancu AC, Olinic M, Tataru D, Spinu M, Olinic DM, Burzotta F, Trani C and Erglis A: How should I treat this mini-crush stenting complication? EuroIntervention 13(10): 1248-1252, 2017. PMID: 29151440. DOI: 10.4244/EIJD-16-00689

8 Olinic DM, Spinu M, Homorodean C and Olinic M: Vasa vasorum induced LAD dissection and haematoma in an anterior STEMI patient with nearly normal angiography: the role of OCT. Kardiol Pol 75(5): 504, 2017. PMID: 28530025. DOI: 10.5603/KP.2017.0082

9 Homorodean C, Spinu M, Ober MC, Olinic M and Olinic DM: Spontaneous coronary dissection: optical coherence tomography insights before and after stenting. Cardiol J 24(2): 217-218, 2017. PMID: 28421589. DOI: 10.5603/CJ.2017.0041

10 Souteyrand G, Valladier M, Amabile N, Derimay F, Harbaoui B, Leddet P, Barnay P, Malcles G, Mulliez A, Berry C, Eschalier $\mathrm{R}$, Combaret $\mathrm{N}$ and Motreff P: Diagnosis and management of spontaneously recanalized coronary thrombus guided by optical coherence tomography - lessons from the french "lotus root" registry. Circ J 82(3): 783-790, 2018. PMID: 29199266. DOI: 10.1253/circj.CJ-17-0810

11 Cho JM, Raffel OC, Stone JR, Kim CJ and Jang IK: Spontaneous recanalization of a coronary artery after thrombotic occlusion: in vivo demonstration with optical coherence tomography. J Am Coll Cardiol 55(12): 1274, 2018. PMID: 20298935. DOI: 10.1016/j.jacc.2008.11.071

12 Kato M, Dote $\mathrm{K}$ and Sasaki S: Recanalized image of thrombotic occlusion with coronary plaque rupture: a lotus root-like appearance by optical coherence tomography. Can J Cardiol 27(6): 871-872, 2011. PMID: 22014625. DOI: 10.1016/j.cjca.2011.08.125

13 Estévez-Loureiro R, Calviño-Santos R, Salgado-Fernández J, López-Sainz A, García-Guimaraes M, Piñón-Esteban P, AldamaLópez G, Vazquez-Gonzalez N and Castro-Beiras A: Image of a chronic recanalized thrombus by intracoronary imaging: intravascular ultrasound and optical coherence tomography analysis. JACC Cardiovasc Interv 5(11): e33-34, 2012. PMID: 23174649. DOI: 10.1016/j.jcin.2012.08.008

14 Toutouzas K, Karanasos A, Stathogiannis K, Synetos A, Tsiamis E, Papadopoulos D and Stefanadis C: A honeycomb-like structure in the left anterior descending coronary artery: demonstration of recanalized thrombus by optical coherence tomography. JACC Cardiovasc Interv 5(6): 688-689, 2012. PMID: 22721666. DOI: 10.1016/j.jcin.2012.01.024

15 Gómez-Monterrosas O, Regueiro A, Santos A, Otsuki S, Scalone G, Fernández-Rodríguez D and Sabaté M: Recanalized thrombus treated with bioresorbable vascular scaffold: insights from optical coherence tomography. JACC Cardiovasc Interv 7(12): 1453-1455, 2014. PMID: 25457058. DOI: 10.1016/j.jcin. 2014.07.015

16 Koyama K, Yoneyama K, Mitarai T, Kuwata S, Ishibashi Y, Kongoji $\mathrm{K}$ and Akashi YJ: In-stent protrusion after implantation of a drug-eluting stent in a honeycomb-like coronary artery structure: complete resolution over 6 months and the role of optical coherence tomography imaging in the diagnosis and follow-up. JACC Cardiovasc Interv 7(5): e39-40, 2014. PMID: 24746653. DOI: 10.1016/j.jcin.2013.07.023

17 Musashi M, Tada N, Uemura N, Kawashima O, Ootomo T, Inoue $\mathrm{N}, \mathrm{Abe} \mathrm{H}$ and Meguro T: Multivessel honeycomb-like structure finding in optical coherence tomography. JACC 
Cardiovasc Interv 7(2): e7-e8, 2014. PMID: 24556108. DOI: 10.1016/j.jcin.2013.04.028

18 Yang DH, Kang SJ, Kim YH, Kang JW, Ahn JM, Park DW, Lee SW, Lee CW, Park SW, Park SJ and Lim TH: Recanalization of organized thrombi demonstrated by coronary CT angiography compared with OCT. JACC Cardiovasc Imaging 9(7): 887-890, 2016. PMID: 27209107. DOI: 10.1016/j.jcmg.2015.09.023

19 Watanabe Y, Fujino Y, Ishiguro $H$ and Nakamura $S$ : Recanalized thrombus treated with a paclitaxel-coated balloon: Insights from optical coherence tomography. JACC Cardiovasc Interv 9(6): 618-620, 2016. PMID: 27013163. DOI: 10.1016/j.jcin.2015.12.007

20 Suzuki S, Sotomi Y, Nakatani S, Hirata A, Hao H, Tsujimoto M, Tsuji H, Shiojima I, Sakata Y, Hirayama A and Higuchi Y: Histopathologic insights into the honeycomb-like structure in the coronary artery: In vivo multimodality imaging assessment with directional coronary atherectomy. JACC Cardiovasc Interv 11(19): e157-e159, 2018. PMID: 30286864. DOI: 10.1016/ j.jcin.2018.07.014

21 Kimura T, Itoh T, Fusazaki T, Nakamura M and Morino Y: A honeycomb-like structure in the right coronary artery visualized by three-dimensional optical coherence tomography. Coron Artery Dis 26(4): 356-360, 2015. PMID: 25647460. DOI: 10.1097/MCA.0000000000000217

22 Seike F, Kawakami H, Oshita A and Matsuoka H: A recurrent coronary honeycomb-like structure: insights from angioscopy and optical coherence tomography. Coron Artery Dis 27(4): 331333, 2016. PMID: 26807622. DOI: 10.1097/MCA.0000000 000000346

23 Dai K, Nakao Y, Kobayashi Y, Ikegami Y, Takeuchi A, Harima A, Higaki T, Oi K, Kawase T, Nakama Y, Suenari K, Nishioka K, Sakai K, Otsuka M, Shimatani Y, Masaoka Y, Shiode N, Inoue I and Ishihara M: Findings of optical frequency domain imaging and coronary angioscopy in a lesion with spontaneous recanalization identified by serial coronary angiography. Coron Artery Dis 28(4): 353-354, 2017. PMID: 28045697. DOI: 10.1097/MCA.0000000000000448

24 Karamasis GV, Chotai S, Khokhar AA and Kelly PA: Recanalized chronic coronary thrombus: unraveling a hazy coronary lesion by intravascular ultrasound. Cardiovasc Diagn Ther 6(2): 185-187, 2016. PMID: 27054109. DOI: 10.21037/ cdt.2015.12.10

25 Haraki T, Uemura R, Masuda S, Kobayashi N and Lee T: A honeycomb-like structure in the left anterior descending coronary artery treated using a scoring device and drug-eluting stent implantation: a case report. J Med Case Rep 10: 80, 2016 PMID: 27036624. DOI: 10.1186/s13256-016-0874-y

26 Silenzi S, Mariani L, Grossi P, Aimi A, Di Vito L and Moretti L: A patient with multiple Swiss cheese aspect coronary lesions: optical coherence tomography to guide coronary angioplasty. Future Cardiol 14(5): 375-380, 2018. PMID: 30232905. DOI: 10.2217/fca-2018-0035

27 Niizeki T, Ikeno E, Iwayama T and Watanabe M: Difficult wiring of a recanalized thrombotic lesion in the right coronary artery analyzed with optical coherence tomography. Am J Case Rep 19: 941-945, 2018. PMID: 30097560. DOI: 10.12659/ AJCR.910166

28 Khoueiry GM, Magnus P, Friedman BJ and Kaplan AV: Honeycomb-like appearance of hazy coronary lesions: OCT image report of a recanalized thrombus. Eur Heart J Cardiovasc Imaging 15(12): 1427, 2014. PMID: 25082228. DOI: 10.1093/ ehjci/jeu132

29 Fujino Y, Attizzani GF, Tahara S, Takagi K, Naganuma T, Nakamura $S$ and Nakamura S: A honeycomb-like structure in chronic total occlusion demonstrated by frequency-domain optical coherence tomography. Int J Cardiol 186: 239-240, 2015. PMID: 25828125. DOI: 10.1016/j.ijcard.2015.03.251

30 Sakurai S, Takashima H, Waseda K, Ando H, Kurita A and Amano T: Multiple recanalized images of thrombotic occlusion 19 years after percutaneous coronary intervention: insights from optical coherence tomography and intravascular ultrasound. Int J Cardiol 172(2): 480-481, 2014. PMID: 24491858. DOI: 10.1016/j.ijcard.2014.01.014

31 Lin M, Su Z, Li J, Nie R and Wang J: Honeycomb-like structure in the right coronary artery treated with a drug-eluting stent: a case report and literature review. J Int Med Res 46(5): 20082013, 2018. PMID: 29529896. DOI: 10.1177/03000605 18757605

32 Kadowaki H, Taguchi E, Kotono Y, Suzuyama H, Yoshida M, Miyamoto S, Sakamoto T, Nishigami K and Nakao K: A lotus root-like appearance in both the left anterior descending and right coronary arteries. Heart Vessels 31(1): 124-128, 2016. PMID: 25142445. DOI: 10.1007/s00380-014-0567-7

33 Olinic D, Nedevschi S, Feier C, Gal Z and Olinic N: A structured medical text field of DICOM 3.0 transesophageal echocardiography image file for database implementation. 26th Annual Meeting Proceedings volume, IEEE Computers Society Press, Los Alamitos, Computers in Cardiology Conference, Hannover 26: 443-446, 1999.

34 Homorodean C, Olinic D, Nedevschi S and Olinic N: Templates implementation for structured DICOM diagnosis reporting in echocardiography. Computers in Cardiology Conference 32: 379-382, 2005.

35 Homorodean C, Olinic M and Olinic D: Development of a methodology for structured reporting of information in echocardiography. Med Ultrason 14(1): 29-33, 2012. PMID: 22396936.

36 Marc MC, Iancu AC, Ober CD, Homorodean C, Bãlãnescu S, Sitar AV, Bolboacã S, and Dregoesc IM: Pre-revascularization coronary wedge pressure as marker of adverse long-term left ventricular remodeling in patients with acute ST-segment elevation myocardial infarction. Sci Rep 8: 1897, 2018. PMID: 29382891. DOI: 10.1038/s41598-018-20276-6

37 Homorodean C, Iancu AC, Dregoesc IM, Spînu M, Ober MC, Tãtaru D, Leucuţa D, Olinic M and Olinic DM: Renal failure impact on the outcomes of ST-segment elevation myocardial infarction patients due to a left main coronary culprit lesion treated using a primary percutaneous coronary intervention. $\mathrm{J}$ Clin Med 8(4) pii: E565, 2019. PMID: 31027307. DOI: $10.3390 /$ jcm 8040565

38 Canale ML, Camerini A, Huqi A, Lilli A, Bisceglia I, Parrini I, Lestuzzi C, Del Meglio J, Donati S, Venturini E, Sgambato A, Tarantini L, Amoroso D and Casolo G: Cardiovascular risk factors and timing of anthracyclines and trastuzumab cardiac toxicity. Anticancer Res 39(10): 5741-5745, 2019. PMID: 31570476. DOI: 10.21873/anticanres.13775

39 Ciortea R, Mihu D and Mihu CM: Association between visceral fat, IL-8 and endometrial cancer. Anticancer Res 34(1): 379-383, 2014. PMID: 24403491. 
40 Canale ML, Bisceglia I, Lestuzzi C, Parrini I and ANMCO Cardio-Oncology Task Force: Arterial thrombosis in cancer: Spotlight on the neglected vessels. Anticancer Res 39(9): 46194625, 2019. PMID: 31519559. DOI: 10.21873/anticanres.13642

41 Leone AM, Cialdella P, Lassandro Pepe F, Basile E, Zimbardo G, Arioti M, Ciriello, D'Amario D, Buffon A, Burzotta F, Porto I, Aurigemma C, Niccoli G, Rebuzzi AG, Trani C and Crea F: Fractional flow reserve in acute coronary syndromes and in stable ischemic heart disease: Clinical implications. Int J Cardiol 277: 42-46, 2019. PMID: 30107947. DOI: 10.1016/ j.ijcard.2018.08.024
42 Hakeem A, Almomani A and Uretsky BF: Role of fractional flow reserve in the evaluation and management of patients with acute coronary syndrome. Curr Opin Cardiol 32: 767-775, 2017. PMID: 28799978. DOI: 10.1097/HCO.0000000000000448

Received October 31, 2019

Revised November 8, 2019 Accepted November 19, 2019 